\title{
ECOLOGICAL FLOW PROCESS EVALUATION OF A HYDROPOWER STATION'S DEHYDRATION RIVER
}

\author{
DAI, L. - FANG, G. - HUANG, X.* - ZHONG, J. \\ College of Water conservancy and Hydropower Engineering, Hohai University \\ 1 Xikang Rd. Nanjing, 210098 Jiangsu, P.R China \\ *Corresponding author \\ e-mail: hxfhuang2005@163.com; phone: +86-1-599-626-7968
}

(Received 11 $1^{\text {th }}$ Jan 2019; accepted $8^{\text {th }}$ Mar 2019)

\begin{abstract}
We investigated the ecological restoration problems of dehydration river reaches, which are downstream of diversion-type hydropower station in medium and small watersheds. Based on this information, we calculated the ecological flow using the following five methods: the minimum monthly ecological flow method, the dynamic calculation method of ecological water demand, the Northern Great Plains Resource Program method (NGPRP), and the monthly frequency method. Then, we combined Matter Element Analysis (ME) and Tennant method to construct a ME-Tennant model. Furthermore, the ecological flow process of a river was evaluated with ME-Tennant model. The case study was performed at the Liujiaping Hydropower Station in Hunan Province, China. In this study, ME-Tennant evaluation model was applied to determine the ecological flow process, and the results were used to verify the validity and the applicability of the model. The study provides a basis for the ecological restoration of dehydration river reaches, which are downstream of the diversion-type hydropower stations. The proposed evaluation model does provide a new way to reasonably determine the ecological flow process of a river.

Keywords: river reaches, minimum ecological flow, matter element analysis method, ME-Tennant method, Liujiaping hydropower station
\end{abstract}

\section{Introduction}

Diversion-type hydropower stations are generally built in mountain reaches using a pipeline or artificial channels that lead water to the downstream. Diversion-type hydropower stations, which have small flow but large slope, utilizes the large water head to generate electricity. To construct the diversion-type hydroelectric power station, the runoff of the river is divided and dehydration river reaches are formed between the dumpsite and tail water stream. However, a diversion-type hydroelectric power station has adversely affected the quality of river water, causing harm to the ecological environment; moreover, it has negatively impacted the hydrology and the number of water resources in a given area. By maintaining the ecological runoff and its variation characteristics in a river, we can protect the ecosystem of a river and ensure its normal ecological functions. To offer protection to a river ecosystem and to restore its normal functioning, we need to essentially study the ecological runoff process of a river. Both Chinese and international scholars have proposed the idea of ecological runoff calculation. To fulfill this objective, they have used a variety of methods to calculate the ecological runoff of a river. After comparison and analysis of various methods, they have selected the calculation methods and results that reflect the actual situation of rivers. Zhang used five methods to study hydrology and ecological flow of the Pearl River basin. Thus, the ecological runoff of the Pearl River basin was calculated by five methods. By comparing the results with those of Tennant method, he preferred to use the minimum monthly ecological flow method and the monthly frequency method to calculate the minimum ecological runoff and the suitable ecological runoff, respectively 
(Zhang, 2010); Shi used four hydrological methods to calculate the ecological flow, which was produced by the main rivers in Xiangyang City; the methods complied with the requirements of the river ecological water, and they were used to determine the basic ecological flow (Shi and Zuo, 2017). Yu used six methods to calculate the ecological base flow in Guanzhong section of Weihe River. Then, they analyzed the annual runoff distribution characteristics of Weihe River. The results indicated that the Tennant method produced the most accurate results, so it was the best method for calculating the ecological base flow of Weihe River (Palau and Alcázar, 2012). Palau used several methods to determine the minimum ecological flow, and they used BFM method to calculate it (Zhang, 2008).

Different methods may be used to calculate the ecological runoff of different rivers. A single method may produce unreasonable results for different rivers, so a variety of methods should be used to calculate and analyze the ecological runoff of different rivers. However, in this process, the evaluation is not accurate and intuitive enough as it subject to different factors, causing some difficulties in the final determination of ecological runoff. To tackle this situation, we combined Matter Element (ME) analysis and Tennant method to come up with an ME-Tennant model. This model was used to evaluate the ecological flow process of a river. Our main aim was to restore the ecology of dehydrated river reaches, which were located downstream of the diversion-type hydropower stations. Moreover, the ME-Tennant model was projected as a new way of reasonably determining the ecological flow process of a river.

\section{Materials and Methods}

\section{Materials}

The Liujiaping hydropower station is selected as the study area. Its coordinate is 11036 'E-1100 42'E and $27026^{\prime} \mathrm{N}-27038^{\prime} \mathrm{N}$. Liujiaping River is the primary tributary of Erdu River, which originates from Liangfengjie Mountain, Longhui County, Hunan Province, China. The river is zigzagged and it flows from the southeast to the northwest regions of China. In total, the area and length of the river basin area are $72 \mathrm{~km}^{2}$ and $30 \mathrm{~km}$, respectively. A large slope is a characteristic feature of the Erdu River basin. The conditions of the natural river are not conducive for fish farming, and there is no valuable and rare aquatic organism in the river. The basin belongs to the monsoon regions of Southeast Asia. Liujiaping reservoir is located in Longzhuangwan Village, Xupu County. In the reservoir, the rainwater harvesting area is $53.63 \mathrm{~km}^{2}$, while the length of the mainstream above the dam site is $21.0 \mathrm{~km}$. The average slope of the river is $91 \%$, and the total reservoir capacity is $33.652 \times 10^{6} \mathrm{~m}^{3}$.

Liujiaping powerhouse is located approximately $3 \mathrm{~km}$ away in the downstream of the dam. It is a diversion-type hydroelectric power station, which should be regulated for multiple times in a year. There are dehydration river reaches between the dam site and the tail water stream, and a little pond is observed in the foundation pit; the riverbed sand is exposed and there is no habitat for the fish to survive and thrive. A definite ecological flow should be discharged to meet the requirements of ecological environment and water demands of the dehydration river reaches, which are downstream.

An ecological runoff refers to a flow of a certain quality, which is required to maintain the ecological function of a specific river ecosystem; it is affected by the river's ecohydrology and the changes inflicted with temporal and spatial variation. The ecological flow corresponds with the time axis. Therefore, we drew a response curve of 
flow and time, which is known as ecological runoff process (Li, 2015). An ecological runoff process emphasizes the changing characteristics of an ecological flow, which is determined with respect to space and time scales and dynamic demands. It reflects the different requirements of ecological flow in different time-scales.

In order to protect the ecological conditions of dehydration river reaches, a certain ecological flow should be discharged (Wang, 2014); moreover, the ecological runoff process should be performed according to ecological flow requirements of each month. The ecological flow process of dehydration river reaches has many goals, and their implementation sequences are as follows: (1) ensure continuous flow; (2) provide a minimum living space for aquatic organisms; (3) provide suitable habitat conditions for aquatic organisms.

\section{Calculation methods of ecological flow process}

Presently, more than 200 kinds of calculation methods are used to determine the ecological flow of a river (Thame, 2003); these methods are mainly classified into four types: i) the hydrologic method is based on the historical hydrological flow data, such as the Tennant method; ii) the hydraulic method is based on hydraulic foundation and cross-section parameters used for calculation, such as the R2-Cross method and the wetted perimeter method; iii) the habitat simulation method is based on biological factors, which are combined with the results of hydraulic analysis and habitat evaluation. For example, the instream flow incremental method (IFIM method) and physical habitat model simulation method (PHABSIM method); and iv) the holistic analysis method is based on the theory of river system integrity, which is combined with the flow data and information. The overall evaluation method and the BBM method (Building Block Methodology) are the most commonly used methods of this type.

Due to a lack of ecological data, it is difficult to apply the following methods in China: the habitat simulation method, the hydraulic method, and the holistic analyze method. However, hydrology method only needs historical flow data to ascertain the ecological flow of a river, and most of China's regional historical flow data is sufficient; therefore, hydrology method is quite appropriate for use in China. Moreover, the method can be suitably used to analyze the research data of small and medium-sized rivers' ecological flow. In this study, we analyzed several common hydrological methods.

\section{The minimum monthly ecological flow method}

In the monthly minimum ecological flow method, the ecological flow of each month is calculated from the minimum monthly average flow observed in the historical runoff series of several years. With this method, we calculated the minimum ecological flow process (Yu, 2004). The formula is as follows:

$$
q_{i}=\min \left(q_{i j}\right), j=1,2, \ldots n
$$

where, $q_{i}$ is the minimum ecological flow of the month $\mathrm{i}$, and it is expressed in $\mathrm{m}^{3} / \mathrm{s}$; $q_{i j}$ is the average monthly flow of the month $\mathrm{i}$ in the year $\mathrm{j}$, and it is expressed in $\mathrm{m}^{3} / \mathrm{s} ; \mathrm{n}$ is the statistical year. 


\section{The dynamic calculation method of ecological water demand}

The dynamic calculation method was based on the historical flow data, and it introduced the mean value ratio of the same period (Pan and Ruan, 2015; Pan, 2013); moreover, it was also used to determine the relationship between the monthly ecological flow and the annual average flow of each month. Thus, we determined the minimum ecological flow process. The concrete calculation process is as follows:

(1) Calculate the annual average and the minimum annual flow using a long series of natural flow data.

$$
\begin{gathered}
\bar{Q}=\frac{1}{12} \sum_{i=1}^{12} \bar{q}_{i} \\
\bar{Q}_{\min }=\frac{1}{12} \sum_{i=1}^{12} q_{\min (i)} \\
q_{\min (i)}=\min \left(q_{i j}\right), j=1,2, \ldots n
\end{gathered}
$$

where, $\bar{Q}$ is the annual average flow, and it is expressed in $\mathrm{m}^{3} / \mathrm{s} ; \bar{q}_{i}$ is the annual average monthly flow of each month $\mathrm{i}$, and it is expressed in $\mathrm{m}^{3} / \mathrm{s} ; \bar{Q}_{\min }$ is the minimum annual average flow, and it is expressed in $\mathrm{m}^{3} / \mathrm{s} ; q_{\min (i)}$ is the minimum monthly average flow of the month $\mathrm{i}$ in several years, and it is expressed in $\mathrm{m}^{3} / \mathrm{s} ; q_{i j}$ is the monthly average flow of month $i$ in year $j$, and it is expressed in $\mathrm{m}^{3} / \mathrm{s} ; n$ is the statistical number.

(2) Calculate the mean value ratio of the same period according to the annual average flow and the minimum annual average flow:

$$
\eta=\bar{Q}_{\min } / \bar{Q}
$$

(3) Calculate the monthly ecological flow according to the annual average monthly flow:

$$
Q_{i}=\bar{q}_{i} \times \eta
$$

where, $Q_{i}$ is the ecological flow of month i, and it is expressed in $\mathrm{m}^{3} / \mathrm{s}$.

\section{NGPRP method}

In the Northern Great Plains Resource Program method (NGPRP), the hydrological year group was classified into three types: low flow year group, normal flow year group, and flood year group. This method confirms that each month flow can be included in the normal flow year group, with a guaranteed rate of $90 \%$. The minimum ecological flow is calculated by this approach (Wang, 2015). The anomaly percentage method was used to divide the group. 


$$
P_{i}=\left(Q_{i}-Q_{a}\right) / Q_{a}
$$

where, $\mathrm{P}_{\mathrm{i}}$ is the anomaly percentage of annual average flow, and it is expressed in $\%$. When $-10 \% \leq \mathrm{Pi} \leq 10 \%$, it belongs to the normal flow year group; $\mathrm{Q}_{\mathrm{i}}$ is the annual average flow of year $\mathrm{i}$, and it is expressed in $\mathrm{m}^{3} / \mathrm{s} ; \mathrm{Q}_{\mathrm{a}}$ is the annual average flow of several years, and it is expressed in $\mathrm{m}^{3} / \mathrm{s}$.

\section{Monthly frequency method}

In the monthly frequency method, the year is divided into different periods by referring to the historical monthly flow data. Then, different guarantee rates are selected to calculate the flow of each period, and this information is an estimate of the ecological flow process. To select different guarantee rates for each period, we referred to the main research studies of prominent scholars: Yu first proposed the monthly frequency method to calculate the ecological flow of Luohe River and Yihe River, and he assumed that the guaranteed rate of monthly flow was $80 \%$ in winter, $75 \%$ in spring and autumn, $50 \%$ in summer; these guaranteed rates of monthly flow were considered as the river's ecological flow in different seasons. Li proposed that the guaranteed rate of month flow was always greater than $50 \%$ in each month (Li, 2007). Guo assumed the guaranteed rate of monthly flow as $80 \%$ in the low water period and $50 \%$ in the normal flow period. For the flood period, he directly took the annual average flow as the ecological flow (Guo, 2008). In this study, the small river flow was divided into three phases: the low flow period, the normal flow period, and the flood period; the different selections of guaranteed rate are as follows: i) $90 \%$ in the low flow period, $80 \%$ in the normal flow period, and $50 \%$ in the flood period; ii) $50 \%$ guaranteed rate for each month; and iii) $80 \%$ in the low flow period, $50 \%$ in the normal flow period, and the annual average flow in the flood period.

\section{Tennant method}

The ecological flow was calculated using the Tennant method: a percentage of the annual average flow of the river channel was considered as the recommended flow (Xu, 2003), and different percentages were considered in different months. Moreover, the year was divided into the spawning period (April-September) and the general period (October-March) of water use. Table 1 elucidates the relation between the channel flow and the river's ecological health in each period.

Table 1. The relation between the channel flow and the river ecological health

\begin{tabular}{c|c|c}
\hline \multirow{2}{*}{ River ecological health } & \multicolumn{2}{|c}{ The percentage of channel flow accounts for annual average flow } \\
\cline { 2 - 3 } & General using water period (Oct-Mar.) & Spawning period (Apr-Sept.) \\
\hline Maximum & 200 & 200 \\
Optimum range & $60 \sim 100$ & $60 \sim 100$ \\
very good & 40 & 60 \\
good & 30 & 50 \\
preferably & 20 & 40 \\
average or inferior & 10 & 30 \\
Poor or minimum & 10 & 10 \\
Severe degradation & $<10$ & $<10$ \\
\hline
\end{tabular}


In practical application, many Chinese scholars have modified the Tennant method to suit the specific conditions of the study area. Zhang Mei calculated ecological flow by dividing the year into non-flood period (November-May) and flood period (JuneOctober) (Zhang, 2005). He considered the specific characteristics of the water diversion area in the west route of South-to-North Water Transfer Project. Zheng Zhihong emphasized the obvious seasons variations of North China River; the river's ecological water demand period was further classified into three different periods by considering a seasonal variation. For each period, the percentage of recommended base flow was reselected according to the expert suggestion (Zhen, 2010). Chen proved that the ecological flow of Yellow River was different in the following two periods: the nonflood period (November-July) and flood period (July-October). After analyzing the characteristics of Yellow River in each period, they further derived a new percentage coefficient by multiplying the bed gradient: this parameter was more suitable for the sandy river (Chen, 2011).

To perform the minimum monthly ecological flow method, we require hydrological data of more than 20 years; however, the calculation process is simple, and the minimum ecological flow can meet the minimum living conditions of aquatic organisms. Nevertheless, it is not conducive for the healthy development of the aquatic ecosystem in the long-term. To determine ecological water demand by the dynamic calculation method, we have to calculate the mean value ratio of the same period; this method rectifies the subjectivity and experience of the traditional hydrological method, and it reflects the change characteristics of river flow in times of abundance and drought; however, the method does not apply to strong seasonal rivers. Furthermore, NGPRP method takes into account climatic conditions, acceptable frequency factors, and the difference between the normal flows of different years, but the method lacks a biological basis. The monthly frequency method considers the different requirements of the ecological system in different periods; different assurance rates are chosen to ensure that the ecological flow process adapts with the natural flow process, but it is difficult to select the most reasonable assurance rate. The Tennant method is simple and convenient, but it does not analyze the flow characteristics from the river basin's characteristics; moreover, there are no formation rules. It is usually used to analyze a river of low priority or to inspect the results of other methods.

Both advantages and disadvantages are encountered when we use different methods to calculate ecological flow. The basin's geographical location, climate, underlying surface, and the influencing human activities are considered when we use a variety of calculation methods. Thus, an unreasonable result of ecological flow can be definitely avoided. However, the suitable methods used for calculating the ecological flow of different river types are different; therefore, the calculation results will be different when we use a variety of methods to calculate the ecological flow of a river. Furthermore, we also encountered some difficulties in the final determination of the ecological runoff process. Therefore, it is important to objectively evaluate the ecological flow process, which was calculated by different methods. The evaluation results can serve as the basis for the determination of ecological flow process. In this study, we proposed an evaluation model based on ME-Tennant method. This model was specifically developed to calculate the ecological flow process of a river. 


\section{Ecological flow process evaluation model based on ME-Tennant method}

The matter element analysis method is based on the following principle: everything can be described by three elements-"things $\mathrm{N}$, the characteristics of things $\mathrm{C}$, the corresponding value of the characteristics $X^{\prime \prime}$ which are basic elements of an ordered triple. These are known as matter elements. Using the ordered triple $R=(N, C, X)$, we describe things as basic elements (Feng and Hong, 2014).

(1) Construct the matter element matrix

The ecological flow conditions of 12 months were used as evaluation indexes of the ecological flow process, and we recorded them as 12 characteristics. The matter element matrix was established as follows:

$$
R=\left(\begin{array}{ccc}
P_{0} & C_{1} & X_{1} \\
& C_{2} & X_{2} \\
& \vdots & \vdots \\
& C_{n} & X_{n}
\end{array}\right)
$$

where, $\mathrm{R}$ is the $\mathrm{n}$-dimension matter element; $\mathrm{P}_{0}$ is the unevaluated unit of the ecological flow process; $C_{i}(i=1,2 \ldots n)$ is the $\mathrm{i}$-th evaluation index, which is the ecological flow condition of month $\mathrm{i} ; X_{i}(i=1,2 \ldots n)$ is the corresponding value of the evaluation index $\mathrm{C}_{\mathrm{i}}$, and the percentage of the ecological flow of month $\mathrm{i}$ accounts for the annual average flow.

(2) Construct the classical domain and the joint domain matter-element

The classical domain and the joint domain matter-element were constructed according to the evaluation criterion of the ecological flow process.

The classical domain matter-element $R_{j}$ can be expressed as follows:

$$
R_{j}\left(N_{j}, C, X_{j}\right)=\left(\begin{array}{ccc}
N_{j} & C_{1} & X_{j 1} \\
& C_{2} & X_{j 2} \\
& \vdots & \vdots \\
& C_{n} & X_{j n}
\end{array}\right)=\left(\begin{array}{ccc}
N_{j} & C_{1} & {\left[a_{j 1}, b_{j 1}\right]} \\
& C_{2} & {\left[a_{j 2}, b_{j 2}\right]} \\
& \vdots & \vdots \\
& C_{n} & {\left[a_{j n}, b_{j n}\right]}
\end{array}\right)
$$

where, $N_{j}(j=1,2 \ldots m)$ is the $\mathrm{j}$-th grade of the ecological flow process; $X_{j i}=\left[a_{j i}, b_{j i}\right]$ is the classical domain, representing the percentage range of the ecological flow that accounts for the annual average flow corresponding with the $j$-th grade.

The joint domain matter-element can be expressed as follows:

$$
R_{p}\left(N_{p}, C, X_{p}\right)=\left(\begin{array}{ccc}
N_{p} & C_{1} & X_{p 1} \\
& C_{2} & X_{p 2} \\
& \vdots & \vdots \\
& C_{n} & X_{p n}
\end{array}\right)=\left(\begin{array}{ccc}
N_{p} & C_{1} & {\left[a_{p 1}, b_{p 1}\right]} \\
& C_{2} & {\left[a_{p 2}, b_{p 2}\right]} \\
& \vdots & \vdots \\
& C_{n} & {\left[a_{p n}, b_{p n}\right]}
\end{array}\right)
$$


where, $N_{p}$ is the set of evaluation grade; $X_{p i}=\left[a_{p i}, b_{p i}\right]$ is the joint domain, which represents the sum of the numerical range of the classical domain of each index.

(3) Determine the correlation function and the correlation degree.

The correlation function indicates that when the value of the matter element is taken as a point on the real axis, the conformity degree of the matter element lies within the required range of values. If $\left|X_{o}\right|=|b-a|$ is used to represent the length of the bounded interval $X_{0}=[a, b]$, the distance from $x_{i}$ to $X_{j i}=\left[a_{j i}, b_{j i}\right]$ and $x_{i}$ to $X_{p i}=\left[a_{p i}, b_{p i}\right]$, respectively:

$$
\begin{aligned}
& \rho\left(x_{i}, X_{j i}\right)=\left|x_{i}-\frac{1}{2}\left(a_{j i}+b_{j i}\right)\right|-\frac{1}{2}\left(b_{j i}-a_{j i}\right)= \begin{cases}a_{j i}-x_{i}, & x_{i} \leq \frac{a_{j i}+b_{j i}}{2} \\
x_{i}-b_{j i}, & x_{i}>\frac{a_{j i}+b_{j i}}{2}\end{cases} \\
& \rho\left(x_{i}, X_{p i}\right)=\left|x_{i}-\frac{1}{2}\left(a_{p i}+b_{p i}\right)\right|-\frac{1}{2}\left(b_{p i}-a_{p i}\right)= \begin{cases}a_{p i}-x_{i}, & x_{i} \leq \frac{a_{p i}+b_{p i}}{2} \\
x_{i}-b_{p i}, & x_{i}>\frac{a_{p i}+b_{p i}}{2}\end{cases}
\end{aligned}
$$

The calculation formula of the correlation function $K_{j}\left(x_{i}\right)$ is as follows:

$$
K_{j}\left(x_{i}\right)= \begin{cases}\frac{-\rho\left(x_{i}, X_{j i}\right)}{\left|X_{j i}\right|} & x_{i} \in X_{j i} \\ \frac{\rho\left(x_{i}, X_{j i}\right)}{\rho\left(x_{i}, X_{p i}\right)-\rho\left(x_{i}, X_{j i}\right)} & x_{i} \notin X_{j i}\end{cases}
$$

where, $\left|X_{j i}\right|=\left|a_{j i}-b_{j i}\right|$.

(4) Determine the weight of each evaluation index

Weight refers to the importance of an index in the whole index system. Greater the value of the weight, more important it is in the system. To determine the weight of the index, we divided the method into two categories: the subjective weight method and the objective weight method. In this study, an analytic hierarchy process was used to determine the importance of each month's ecological flow (Fan and Jiang, 2001; Fan, 2001). The main steps are as follows:

a) Determine the evaluation target and the evaluation index set

b) Establish a fuzzy consistent judgment matrix

The fuzzy consistent judgment matrix reflects the relative importance degree of each two elements in $a_{1}, a_{2}, a_{3}, \ldots, a_{n}$, and it is expressed as follows: 


$$
R=\left(\begin{array}{ccc}
r_{11} & \cdots & r_{1 n} \\
\vdots & \ddots & \vdots \\
r_{n 1} & \cdots & r_{n n}
\end{array}\right)
$$

where, $r_{i j}$ is the membership degree that indicates how much more important $a_{i}$ is than $a_{j}$; greater the value of $r_{i j}$, more important is $a_{i}$ than $a_{j}$. We used the $0.1-0.9$ scale method (Table 2) to determine it.

Table 2. Scale of 0.1 0.9 measure

\begin{tabular}{c|c|c|c|c|c}
\hline Scale & $\mathbf{0 . 5}$ & $\mathbf{0 . 6}$ & $\mathbf{0 . 7}$ & $\mathbf{0 . 8}$ & $\mathbf{0 . 9}$ \\
\hline Definition & equal important & $\begin{array}{c}\text { slightly more } \\
\text { important }\end{array}$ & $\begin{array}{c}\text { obviously more } \\
\text { important }\end{array}$ & $\begin{array}{c}\text { much more } \\
\text { important }\end{array}$ & $\begin{array}{c}\text { extremely more } \\
\text { important }\end{array}$ \\
\hline
\end{tabular}

The properties of fuzzy judgment consistency matrix R are as follows:

1) $r_{i i}=0.5, \mathrm{i}=1,2,3, \ldots, \mathrm{n}$;

2) $r_{i j}+r_{j i}=1, \mathrm{i}, \mathrm{j}=1,2,3, \ldots, \mathrm{n}$;

3) $r_{i j}=r_{i k}-r_{j k}+0.5, i, j, k=1,2,3, \cdots, n$.

For $\mathrm{R}$ to be a fuzzy consistent judgment matrix, the necessary and the sufficient condition is as follows: there exist an n-order non-negative normalized vector $W=\left(\omega_{1}, \omega_{2}, \cdots, \omega_{n}\right)$ and a positive number a make $\forall i, j$ that satisfy the following condition:

$$
r_{i j}=a\left(\omega_{i}-\omega_{j}\right)+0.5
$$

where, parameter $\mathrm{a} \geq(\mathrm{n}-1) / 2$ (in this paper, set $\mathrm{a}=(\mathrm{n}-1) / 2$ ); the value of a reflects the decision makers' personal preference. Smaller the value of a, more attention would experts pay to the difference between the weight of elements (Lv, 2002).

a) Calculate index weight

Fix the $\mathrm{i}$ in formula (15) and obtain the following equation:

$$
\omega_{i}=\frac{1}{a}\left(r_{i k}-\frac{1}{2}\right)+\omega_{k}, \quad k=1,2,3, \cdots, n
$$

Calculate the sum of $\mathrm{k}$ and obtain the following equation:

$$
n \omega_{i}=\frac{1}{a} \sum_{k=1}^{n} r_{i k}-\frac{n}{2 a}+\sum_{k=1}^{n} \omega_{k}
$$

From the weight vector normalization condition, we obtained the following equation:

$$
\omega_{i}=\frac{1}{n}-\frac{1}{2 a}+\frac{1}{n a} \sum_{k=1}^{n} r_{i k}, \quad i=1,2,3, \cdots, n
$$


In the formula, $0 \leq \omega_{i} \leq 1$.

(5) Calculate the comprehensive correlation degree

$$
K_{j}\left(P_{0}\right)=\sum_{i=1}^{n} \omega_{i} K_{j}\left(x_{i}\right)
$$

where, $K_{j}\left(P_{0}\right)$ is the comprehensive correlation degree of the $\mathrm{j}$-th evaluation grade.

(6) Grade evaluation

If $K_{j}=\max \left\{K_{j}\left(P_{0}\right)\right\}(j=1,2, \cdots, m)$, the ecological flow process is in grade $\mathrm{j}$. When $0<K_{j}\left(P_{0}\right)<1$, it indicates that the unevaluated unit meets the requirements of the standard object. When $-1<K_{j}\left(P_{0}\right)<0$, the evaluation unit can't meet the requirements of the evaluation grade; however, it has the capacity to transform into a form that conforms with the standard. When $K_{j}\left(P_{0}\right)<-1$, the evaluation unit neither meet the requirements nor can it transform. When $K_{j}\left(P_{0}\right)>1$, the evaluation unit exceeds the upper limit of the standard grade.

(7) Determine the ecological flow process

The ecological flow process was determined reasonably using the evaluation grade of the ecological flow process, which was calculated by different calculation methods and combined with the ecological water requirement of the basin.

\section{Results and discussion}

\section{Calculate the ecological flow process}

In this paper, we selected measured monthly flow data of Liujiaping dam site from 1987 to 2015, which is period of 29 years in total. The annual average flow was $1.51 \mathrm{~m}^{3} / \mathrm{s}$. In theory, we must calculate the ecological flow process using natural flow data; however, since 1987, the river was more or less affected by human activities, so the ecological status might not have been restored to the original status. The altered ecosystem was further adapted to the present flow process. In fact, the so-called "natural state" was only considered as the state that was less affected by human activity. After analyzing the period 1987-2015, we found that the average flow of each year was slightly different from the average annual flow; moreover, there was no obvious mutation, indicating that the average annual flow was least affected by human activities. Therefore, the ecological flow process was calculated using the directly measured data instead of the natural flow data. After determining the multi-year average flow process at the dam site, we divided the whole year is divided into three periods: low water period (November-February), normal water period (March-April, September-October), and flood period (May-August). The hydrological frequency analysis was carried out using PIII curve. The minimum monthly ecological flow method, the dynamic calculation method of ecological water demand, the NGPRP method, and the monthly frequency method were used to calculate the ecological flow process of Liujiaping 
hydropower station downstream of the dehydration river reaches. The calculation results are presented in Table 3.

Table 3. The calculation results of ecological flow process by different methods $\mathrm{m}^{3} / \mathrm{s}$

\begin{tabular}{|c|c|c|c|c|c|c|c|c|c|c|c|c|}
\hline $\begin{array}{l}\text { Month } \\
\text { Method } \\
\end{array}$ & 1 & 2 & 3 & 4 & 5 & 6 & 7 & 8 & 9 & 10 & 11 & 12 \\
\hline $\begin{array}{l}\text { Minimum monthly } \\
\text { ecological flow method }\end{array}$ & 0.301 & 0.368 & 0.332 & 0.613 & 1.166 & 1.292 & 1.180 & 0.566 & 0.191 & 0.234 & 0.230 & 0.200 \\
\hline Dynamic calculation method & 0.311 & 0.362 & 0.423 & 0.520 & 0.751 & 0.910 & 1.031 & 0.726 & 0.543 & 0.412 & 0.357 & 0.324 \\
\hline NGPRP & 0.400 & 0.560 & 0.550 & 0.830 & 1.080 & 1.630 & 1.350 & 0.830 & 0.450 & 0.450 & 0.380 & 0.430 \\
\hline $\begin{array}{l}\text { monthly frequency } \\
\text { methodI }\end{array}$ & 0.390 & 0.460 & 0.780 & 1.120 & 1.880 & 2.350 & 2.540 & 1.840 & 0.870 & 0.680 & 0.400 & 0.410 \\
\hline $\begin{array}{l}\text { monthly frequency } \\
\text { method II }\end{array}$ & 0.750 & 0.830 & 1.040 & 1.340 & 1.880 & 2.350 & 2.540 & 1.840 & 1.240 & 0.940 & 0.790 & 0.750 \\
\hline $\begin{array}{l}\text { monthly frequency } \\
\text { method III }\end{array}$ & 0.480 & 0.540 & 1.040 & 1.340 & 1.510 & 1.510 & 1.510 & 1.510 & 1.240 & 0.940 & 0.490 & 0.490 \\
\hline
\end{tabular}

Monthly frequency method (i): $90 \%$ in the low flow period, $80 \%$ in the normal flow period, $50 \%$ in the flood period; monthly frequency method; (ii): $50 \%$ guaranteed rate for each month; monthly frequency method (iii): $80 \%$ in the low flow period, $50 \%$ in the normal flow period, and the annual average flow in the flood period

\section{Evaluation of the ecological flow process based on ME-Tennant method}

According to the present ecological situation of Liujiaping hydropower station downstream, the goals of discharging the ecological flow and their implementation sequences are as follows: (i) ensure a continuous flow; (ii) provide a minimum living space for aquatic organisms; and (iii) provide suitable habitat conditions for aquatic organisms. Because dry flow often occurs in the natural river reach of Liujiaping River during the dry season, we had to offer ecological protection and restoration; therefore, the order of ecological flow conditions and the importance degree of each period is as follows: low flow period $>$ normal flow period $>$ flood period. Drier the month, higher is its importance. Based on this finding, we constructed a fuzzy consistent judgment matrix to elucidate the relative importance of the ecological flow conditions observed in two consecutive months. Moreover, the weight of each month was determined by fuzzy analytic hierarchy process (AHP). The index value $\mathrm{Xi}$ is the percentage of ecological flow of month $\mathrm{i}$, and it accounts for the annual average flow. The classical domain Xji and the joint domain Xp were determined using the evaluation criteria laid down for the river's ecological flow process. As shown in Table 4, the values of indexes, the classical domain, and the joint domain were calculated by the six methods.

We calculated the correlation degree of each evaluation index with respect to each evaluation. By considering the weight of the index, we calculated the comprehensive correlation degree of each evaluation grade. As shown in Table 5, the comprehensive correlation degree and the evaluation results of an ecological flow process were calculated by six different methods. 
Table 4. The values of indexes representing the ecological flow process; the classical domain and the joint domain calculated by different methods

\begin{tabular}{|c|c|c|c|c|c|c|c|c|c|c|c|c|c|}
\hline \multirow{3}{*}{ Index } & \multicolumn{6}{|c|}{ Index value $\mathrm{Xi}$} & \multicolumn{6}{|c|}{ Classical domain $\mathrm{X}_{\mathrm{ji}}$} & \multirow{3}{*}{\begin{tabular}{|c} 
Joint domain \\
$\mathbf{X}_{p}$
\end{tabular}} \\
\hline & \multirow{2}{*}{$\begin{array}{l}\text { Minimum monthly } \\
\text { ecological flow method }\end{array}$} & \multirow{2}{*}{$\begin{array}{c}\text { Dynamic } \\
\text { calculation } \\
\text { method }\end{array}$} & \multirow{2}{*}{ NGPRP } & \multirow{2}{*}{$\begin{array}{c}\text { monthly } \\
\text { frequency } \\
\text { method I }\end{array}$} & \multirow{2}{*}{$\begin{array}{c}\text { monthly } \\
\text { frequency } \\
\text { methodII } \\
\end{array}$} & \multirow{2}{*}{$\begin{array}{c}\text { monthly } \\
\text { frequency } \\
\text { methodIII }\end{array}$} & \multicolumn{3}{|c|}{ Poor AveragePreferably Good } & \multicolumn{3}{|c|}{ Very goodOptimumMaximum } & \\
\hline & & & & & & & $\mathbf{X}_{1 \mathrm{i}} \quad \mathbf{X}_{2 \mathrm{i}}$ & $\mathbf{X}_{\mathbf{3 i}}$ & $\mathbf{X}_{4 i}$ & $\mathbf{X}_{5 i}$ & $\mathbf{X}_{6 i}$ & & \\
\hline $\mathrm{C} 1$ & 19.90 & 20.61 & 26.49 & 25.83 & 49.67 & 31.79 & {$[0,10)[10,20)$} & {$[20,30)$} & {$[30,40)$} & {$[40,60)$} & {$[60,100)$} & {$[100,200]$} & {$[0,200]$} \\
\hline $\mathrm{C} 2$ & 24.37 & 23.98 & 37.09 & 30.46 & 54.97 & 35.76 & {$[0,10)[10,20)$} & {$[20,30)$} & {$[30,40)$} & {$[40,60)$} & {$[60,100)$} & {$[100,200]$} & {$[0,200]$} \\
\hline $\mathrm{C} 3$ & 21.96 & 28.02 & 36.42 & 51.66 & 68.87 & 33.11 & {$[0,20)[20,30)$} & {$[30,40)$} & {$[40,50)$} & {$[50,70)$} & {$[70,100)$} & {$[100,200]$} & {$[0,200]$} \\
\hline $\mathrm{C} 4$ & 40.57 & 34.42 & 54.97 & 74.17 & 88.74 & 53.64 & {$[0,20)[20,30)$} & {$[30,40)$} & {$[40,50)$} & {$[50,70)$} & {$[70,100)$} & {$[100,200]$} & {$[0,200]$} \\
\hline $\mathrm{C} 5$ & 77.19 & 49.71 & 71.52 & 124.50 & 124.50 & 94.70 & {$[0,30)[30,40)$} & {$[40,50)$} & {$[50,60)$} & {$[60,80)$} & {$[80,100)$} & {$[100,200]$} & {$[0,200]$} \\
\hline C6 & 85.54 & 60.29 & 107.95 & 155.63 & 155.63 & 98.10 & {$[0,30)[30,40)$} & {$[40,50)$} & {$[50,60)$} & {$[60,80)$} & {$[80,100)$} & {$[100,200]$} & {$[0,200]$} \\
\hline $\mathrm{C} 7$ & 78.15 & 68.29 & 89.40 & 168.21 & 168.21 & 100.66 & {$[0,30)[30,40)$} & {$[40,50)$} & {$[50,60)$} & {$[60,80)$} & {$[80,100)$} & {$[100,200]$} & {$[0,200]$} \\
\hline $\mathrm{C} 8$ & 37.46 & 48.09 & 54.97 & 121.85 & 121.85 & 86.75 & {$[0,30)[30,40)$} & {$[40,50)$} & {$[50,60)$} & {$[60,80)$} & {$[80,100)$} & {$[100,200]$} & {$[0,200]$} \\
\hline C9 & 12.76 & 35.99 & 29.80 & 57.62 & 82.12 & 38.41 & {$[0,20)[20,30)$} & {$[30,40)$} & {$[40,50]$} & {$[50,70)$} & {$[70,100)$} & {$[100,200]$} & {$[0,200]$} \\
\hline $\mathrm{C} 10$ & 15.53 & 27.27 & 29.80 & 45.03 & 62.25 & 31.79 & {$[0,20)[20,30)$} & {$[30,40)$} & {$[40,50)$} & {$[50,70)$} & {$[70,100)$} & {$[100,200]$} & {$[0,200]$} \\
\hline $\mathrm{C} 11$ & 15.20 & 23.62 & 25.17 & 26.49 & 52.32 & 25.17 & {$[0,10)[10,20)$} & {$[20,30)$} & {$[30,40)$} & {$[40,60)$} & {$[60,100)$} & {$[100,200]$} & {$[0,200]$} \\
\hline $\mathrm{C} 12$ & 13.25 & 21.46 & 28.48 & 27.15 & 49.67 & 25.17 & {$[0,10)[10,20)$} & {$[20,30)$} & {$[30,40)$} & {$[40,60)$} & {$[60,100)$} & {$[100,200]$} & {$[0,200]$} \\
\hline
\end{tabular}

Table 5. The evaluation results of ecological flow process calculated by six different methods

\begin{tabular}{|c|c|c|c|c|c|c|c|c|}
\hline \multirow{2}{*}{ Method } & \multicolumn{7}{|c|}{ Comprehensive correlation degree } & \multirow{2}{*}{$\begin{array}{l}\text { Evaluation } \\
\text { results }\end{array}$} \\
\hline & Poor & Average & Preferably & Good & Very good & Optimum & Maximum & \\
\hline $\begin{array}{c}\text { Minimum monthly } \\
\text { ecological flow method }\end{array}$ & -0.1846 & 0.0423 & -0.1483 & -0.3904 & -0.5098 & -0.6452 & -0.7658 & Average \\
\hline Dynamic calculation method & -0.3196 & -0.0500 & 0.1935 & -0.2254 & -0.3874 & -0.5787 & -0.7220 & Preferably \\
\hline NGPRP & -0.3616 & -0.1946 & 0.1193 & -0.0622 & -0.2277 & -0.4612 & -0.6423 & Preferably \\
\hline $\begin{array}{l}\text { monthly frequency } \\
\text { method I }\end{array}$ & -0.4078 & -0.2743 & 0.0454 & -0.0792 & -0.205 & -0.4107 & -0.5503 & Preferably \\
\hline $\begin{array}{l}\text { monthly frequency } \\
\text { methodII }\end{array}$ & -0.4534 & -0.3956 & -0.3233 & -0.2302 & 0.2179 & -0.0664 & -0.3469 & Very good \\
\hline $\begin{array}{l}\text { monthly frequency } \\
\text { method III }\end{array}$ & -0.4141 & -0.3182 & -0.1756 & 0.0633 & -0.1024 & -0.2209 & -0.4816 & Good \\
\hline
\end{tabular}




\section{Analysis of the evaluation result}

Based on the evaluation results, we present the following observations: the minimum ecological flow process was calculated by different methods; the evaluation grade was "Average" when it was calculated by minimum monthly ecological flow method, but it was "Preferable" when calculated by dynamic calculation method and NGPRP method. In order to ensure a continuous flow and to provide the minimum living space for aquatic organisms, we selected and coupled only those ecological flow processes that had evaluation grades of "Preferable;" we considered the outer envelope curve as the minimum ecological flow process, which was no less than the $10 \%$ of the average annual flow. Table 6 presents the ecological flow of each month in the minimum ecological flow process.

Table 6. The ecological runoff process

\begin{tabular}{|c|c|c|c|c|c|c|c|c|c|c|c|c|}
\hline Month & 1 & 2 & 3 & 4 & 5 & 6 & 7 & 8 & 9 & 10 & 11 & 12 \\
\hline Minimum flow & 0.40 & 0.56 & 0.550 & 0.83 & 1.08 & 1.63 & 1.35 & 0.83 & 0.54 & 0.45 & 0.38 & 0.43 \\
\hline Suitable flow & $0.48-0.7$ & $.54-0.8$ & 31.04 & 1.34 & $.51-1.8$ & $1.51-2.35$ & $1.51-2.5$ & $1.51-1.8$ & 41.24 & 0.94 & $.49-0.79$ & $0.49-0.75$ \\
\hline
\end{tabular}

The minimum ecological flow process is just used to meet the short-term hydrological condition, and it is used as the lower limit to satisfy the river ecosystem's stability and health conditions. Although it can ensure a continuous flow and provide the minimum living space for aquatic organisms, it seems to be harmful for the sustainable development of a river's ecosystem in the long-term. In order to maintain the stability of the basin ecosystem and its function, a suitable ecological flow process should be determined.

To evaluate a suitable ecological flow process, the conditions are as follows: i) the evaluation grade should be "Preferable" for the one calculated by monthly frequency method I ; ii) the evaluation grade should be "Good" for the one calculated by the monthly frequency method III; and iii) the evaluation grade should be "Very good" for the one calculated by the monthly frequency method II. It is important to note that rare aquatic organisms and dense vegetation exist on both the sides of the Liujiaping River Basin, so it is relatively easy to conserve both soil and water in this region; moreover, natural precipitation occurs frequently and groundwater levels are sufficient to supply water. Therefore, when the monthly frequency method II and III have an evaluation grade of "Very good" and "Good," respectively, the ecological water requirements of the river are satisfied by both methods. Thus, we ensure a healthy development of the river's ecosystem. After coupling the two ecological flow processes, we considered the inner envelope curve and the outer envelope curve as the threshold of a suitable ecological flow process. Table 6 presents the ecological flow of each month in the suitable ecological flow process.

At the Liujiaping hydropower station, scientists perform the most important task of power generation. By determining a suitable ecological flow process, we can ensure that the discharge of ecological flow is more flexible in nature. After combining the actual situation of the hydrological conditions and the demand of water and electricity, the generation benefit was considered as the basis of satisfying the ecological water 
requirement. In this way, we improved the efficiency of water usage and the comprehensive benefits of electricity generation.

The minimum ecological flow process and the suitable ecological flow process were determined by taking into account following parameters: the evaluation results, the river's ecological status, and the demand for utilizing water resources in the dehydration river reaches. The minimum ecological flow process can maintain a certain amount of water in the river channel, and it can prevent the ecological condition of the river from deterioration or barrenness. A suitable ecological flow process can ensure that the ecosystem in its best condition, and it can sustain the development of a river's life and health. The two ecological flow processes can reflect the variation of an annual flow; they have a certain reference significance for the ecological protection and restoration of the lower reaches of hydropower stations.

\section{Conclusion}

In this study, we constructed the ME-Tennant model by combining Matter Element Analysis and Tennant method. This model was used to evaluate the ecological flow process of a river. The model was used to evaluate the ecological flow process of dehydration river reaches, which are downstream of Liujiaping Hydropower Station in Hunan Province, China. Furthermore, the minimum ecological flow process and the suitable ecological flow process were determined after analyzing the evaluation results of ecological flow process, which were obtained by six different calculation methods. To restore the ecology of the dehydration river reaches, we can use these evaluation results as a reference.

In the case study, we used the ME-Tennant model to evaluate the ecological flow of the dehydration river reaches. We found that the evaluation grade of a suitable ecological flow process method was greater than that of the minimum ecological flow process calculation method. Moreover, the evaluation results were in good agreement with the actual trends. This indicates that the evaluation results have certain credibility. A percentage of an ecological flow accounted for the annual average flow, which was calculated by the minimum monthly ecological flow method and the dynamic calculation method, were the same but the allocation of annual ecological flow was different. The evaluation model took into account the difference between the important ecological flow conditions of different months, so the evaluation grades were different. The evaluation results were more reasonable. To determine ecological flow process, we developed an evaluation model based on ME-Tennant method. This model was both reasonable and applicable; the evaluation process was simplified and the evaluation result was intuitive. Thus, the ecological flow process can be determined rationally with this innovative model.

Different rivers have different geographical locations, and hydrological conditions; moreover, the impact of human activity is different in different river basins. Furthermore, the ecological flow process method that is most suitable would be different for different rivers. In the evaluation model, the weight of each month, period division, and evaluation criteria should be adjusted according to the watershed situation. Moreover, the ecological data of most small and medium-sized watershed areas are scarce; therefore, the methods involved in this paper are largely based on the historical flow data and the hydrological data, so the hydrological sequence should be checked to ensure the reliability of the data. 
The calculation method of ecological runoff process has high dependence on historical runoff data and requirements. The hydrological sequence should be tested to ensure the reliability of the data. In the process of evaluating and determining the ecological runoff process by applying the ME-Tennant method, due to the different geographical location, hydrological situation and the focus of the river ecological restoration target, the monthly weight, period division and evaluation criteria should be targeted to the basin. Information is adjusted.

Acknowledgements. This work was funded by the Key Project of Water Science and Technology Planning of Hunan Province ([2016]194-21), the fundamental Research Funds for the Central Universities (2019B11014), and the Project of Water Science and Technology Planning of Hunan Province ([2015]245-13).

\section{REFERENCES}

[1] Chen, N., Zhang, D., Jiang, X. (2011): Calculation on eco-environmental water requirements in Huayuankou Station based on an improved Tennant Method. - Journal of North China Institute of Water Conservancy and Hydroelectric Power 32: 23-25.

[2] Fan, Z., Jiang, Y. (2001): Review on the research of fuzzy judgment matrix ranking method. - Systems Engineering 19: 12-18.

[3] Fan, Z., Jiang, Y., Xiao, S. (2001): Consistency of fuzzy judgement matrix and its properties. - Control and Decision 16: 69-71.

[4] Feng, L., Hong, W. (2014): Application of matter element analysis in weather forecasting. - Royal Meteorological Society 21: 398-402.

[5] Guo, L., Xia, Z., Li, J., Ma, G. (2008): Improvement of calculation methods for instream ecological runoff. - Journal of Hohai University (Natural Sciences) 4: 456-462.

[6] Li, J., Xia, Z., Ma, G. (2007): A new monthly frequency computation method for instream ecological flow. - Acta Ecologica Sinica 27: 2916-2921.

[7] Li, B., Yang, B. (2015): Study on ecological runoff process of Liaohe River. - Northeast Water Conservancy and Hydroelectric Power 33: 44-45.

[8] Lv, Y. (2002): Weight calculation method of fuzzy analytical hierarchy process. - Fuzzy Systems Mathematics 16: 79-85.

[9] Palau, A., Alcázar, J. (2012): The Basic Flow Method for Incorporating Flow Variability in Environmental Flows. - River Research and Applications 28: 93-102.

[10] Pan, Z., Ruan, X., Xu, J. (2013): A new calculation method of instream basic ecological water demand. - Journal of Hydraulic Engineering 44: 119-126.

[11] Pan, Z., Ruan, X. (2015): Spatio-temporal analysis of satisfactory degree of ecological water demand in Huaihe River Basin. - Journal of Hydraulic Engineering 46: 280-290.

[12] Shi, Y., Zuo, Q. (2017): The estimation of ecological base flow of main rivers in Xiangyang Citu based on multiple hydrological methods. - China Rural Water and Hydropower 2: 50-54.

[13] Thame, R. E. (2003): A global perspective on environmental flow assessment: emerging trends in the development and application of environmental flow methodologies for rivers. - River Research and Applications 19: 397-441.

[14] Wang, H., Zhou, M., Liu, Y., Li, S. (2014): Hydraulic evaluation methods of ecological water demand by dehydration river reaches of small hydropower plants in Guangdong mountainous areas. - Journal of Hydroelectric Engineering 33: 154-161.

[15] Wang, H., Zhou, M., Li, S., Zhu, J. (2015): Apply hydrological model to evaluation of ecological water demand of dehydration river reaches for small hydropower plants and water supplement. - Journal of Hydroelectric Engineering 34: 29-37. 
[16] Xu, Z., Dong, Z., Zhou, J., Su, F. (2003): Montana method of ecological water requirements and its application. - Water Resources and Hydropower Engineering 11: $15-18$.

[17] Yu, L., Xia, Z., Du, X. (2004): Connotation of minimum ecological runoff and its calculation method. - Journal of Hohai University (Natural Sciences) 32: 18-22.

[18] Zhang, M., Jia, X., Wei, H. (2005): Ecological and environmental water demand in river channels of the first stage water diversion areas from the south to north via the western course. - Resources Science 4: 180-184.

[19] Zhang, L., Li, Liang, L. (2008): Progress on the research of theory and calculation method of ecological water requirement. - Transactions of the Chinese Society of Agricultural Engineering 7: 307-312.

[20] Zhang, Q., Cui, Y., Chen, Y. (2010): Evaluation of ecological instream flow of the Pearl River basin, south China. - Ecology and Environmental Sciences 19: 1828-1837.

[21] Zhen, Z., Zhang, Z., Huang, Q., Qiu, L., Li, Q., Wei, M. (2010): Improvement and application on ecological water requirement Tennant Method. - Journal of Sichuan University (Engineering Science Edition) 42: 34-39. 